\title{
Consumer Rights to Informed Choice on the Food Market
}

\author{
Volkert Beekman
}

Accepted: 11 April 2007 / Published online: 10 May 2007

(C) Springer Science + Business Media B.V. 2007

\begin{abstract}
The discourse about traceability in food chains focused on traceability as means towards the end of managing health risks. This discourse witnessed a call to broaden traceability to accommodate consumer concerns about foods that are not related to health. This call envisions the development of ethical traceability. This paper presents a justification of ethical traceability. The argument is couched in liberal distinctions, since the call for ethical traceability is based on intuitions about consumer rights to informed choice. The paper suggests that two versions of ethical traceability find justification. The first version of ethical traceability entails that governments ensure that all consumers are provided with foods that respect some threshold level of, e.g., animal welfare that is supported by an overlapping consensus. The second version of ethical traceability entails that food producers provide consumers with products, and sufficient information about these products, that are relevant for reasonable, non-superficial values that are not supported by an overlapping consensus. Governments should facilitate this in the sense that consumers are not provided with misinformation about characteristics of foods that are relevant for reasonable, non-superficial values that are not supported by an overlapping consensus.
\end{abstract}

Keywords Consumer concerns $\cdot$ Food ethics $\cdot$ Informed choice $\cdot$ Liberalism $\cdot$ Traceability

\section{Introduction}

Regulatory and scientific discourse about traceability in food production chains hitherto predominantly focused on the development of traceability schemes as means towards the end of managing food-borne health risks. The overall aim of developing traceability schemes within this context of risk management in production chains has been to ensure

\footnotetext{
V. Beekman $(\bowtie)$

Applied Philosophy Group, Wageningen University, Hollandseweg 1, $6706 \mathrm{KN}$ Wageningen, The Netherlands

e-mail: volkert.beekman@wur.nl
} 
that consumers can trust that their consumption of food products as provided on the market is not risky in terms of health consequences.

This regulatory and scientific discourse recently witnessed a call to broaden the established notion of traceability to accommodate consumer concerns about product and process characteristics of foods that are not related to health risks. This call envisions the development of something like ethical traceability. This notion of ethical traceability was introduced by Coff (2004) and may be defined as "the ability to trace and map ethical aspects of the food chain by means of recorded identifications" (Coff et al. 2007). It thus refers to the traceability of ethically relevant product and process characteristics of foods. It should not be confused either with the idea of ethically responsible food safety traceability or with the idea of a moral HACCP that looks at human failure as a critical control point (Hirschauer 2004). ${ }^{1}$

Before engaging in the development of ethical traceability schemes, however, the first question in need of serious scrutiny is the question of why ethical traceability might be a worthwhile objective in the context of the pursuit of a new social contract between food producers, consumers and society at large. In other words, a justification discourse about ethical traceability needs to precede an application discourse. This paper presents a contribution to the justification of ethical traceability. The main line or argument is couched in terms of some basic liberal distinctions, since the call for ethical traceability seems to be based first and foremost on intuitions about consumer rights to informed choice on the food market. This paper is rather strongly embedded in liberal political philosophy as developed - partly in discussion with communitarian and utilitarian political philosophies - after Rawls (1972). ${ }^{2}$ Although consumer freedom is high on the agenda of socio-political debate, this paper explores relatively unknown territory. ${ }^{3}$

The paper starts by introducing the liberal distinctions to be used subsequently. It then argues that the operational domain for ethical traceability should be positioned somewhere between needs like food safety that entail positive unconditional rights of consumers and positive unconditional duties of producers and regulators with respect to the provision and traceability of food products, and non-reasonable and/or superficial wants with respect to food that do not entail any rights and duties. The basic argument is that ethical traceability is operational within the domain of reasonable and non-superficial wants with respect to food, which entail conditional rights of consumers and conditional duties of producers and regulators.

\section{Some Basic Liberal Distinctions}

This section introduces some basic liberal distinctions that inform the main line of argument in this paper (see Table 1). It offers definitions - or rather circumscriptions - of the key terms that are hopefully non-controversial enough to be acceptable for everyone

\footnotetext{
${ }^{1}$ Moral traceability might be a better wording than ethical traceability for scholars with a preference for a more strict distinction between ethical theory and moral practice but this paper prefers to follow the original notion as coined by Coff (2004) and used in the European project 'Ethical traceability and informed choice in food ethical issues.'

${ }^{2}$ Kymlicka (1990) provides a good introduction to the main discussions within contemporary political philosophy.

${ }^{3}$ Four of the few academic papers critically analysing autonomy or freedom of choice in a (food) market context are Beekman (2000), Brom (2000), Rippe (2000) and Korthals (2001).
} 
Table 1 Some basic liberal distinctions

\begin{tabular}{|c|c|c|c|c|}
\hline & Needs & Wants & & \\
\hline Traceability & Traceability & $\begin{array}{l}\text { Ethical traceability } \\
\text { as a management } \\
\text { tool }\end{array}$ & $\begin{array}{c}\text { Ethical traceability as a } \\
\text { communication tool }\end{array}$ & No traceability \\
\hline Values & Food safety & $\begin{array}{l}\text { Reasonable, non- } \\
\text { superficial and } \\
\text { overlapping food } \\
\text { values }\end{array}$ & $\begin{array}{l}\text { Reasonable, non- } \\
\text { superficial and non- } \\
\text { overlapping food values }\end{array}$ & $\begin{array}{l}\text { Non-reasonable } \\
\text { and/or } \\
\text { superficial } \\
\text { food values }\end{array}$ \\
\hline Consumers & $\begin{array}{l}\text { Positive unconditional } \\
\text { right to be provided with } \\
\text { safe foods }\end{array}$ & $\begin{array}{l}\text { Positive conditional } \\
\text { right to be } \\
\text { provided with } \\
\text { foods }\end{array}$ & $\begin{array}{l}\text { Negative conditional } \\
\text { right to be provided } \\
\text { with information about } \\
\text { foods }\end{array}$ & No rights \\
\hline Producers & $\begin{array}{l}\text { Positive unconditional duty } \\
\text { to provide safe foods }\end{array}$ & $\begin{array}{l}\text { Positive conditional } \\
\text { duty to provide } \\
\text { foods }\end{array}$ & $\begin{array}{l}\text { Negative conditional } \\
\text { duty to provide } \\
\text { information about foods }\end{array}$ & No duties \\
\hline Regulators & $\begin{array}{l}\text { Positive unconditional duty } \\
\text { to ensure food safety with } \\
\text { traceability regulation }\end{array}$ & $\begin{array}{l}\text { Positive conditional } \\
\text { duty to regulate } \\
\text { ethical traceability }\end{array}$ & $\begin{array}{l}\text { Negative conditional } \\
\text { duty to facilitate ethical } \\
\text { traceability }\end{array}$ & No duties \\
\hline
\end{tabular}

subscribing to the basic values (liberty, equality and fraternity) of modern liberaldemocratic European societies.

This paper embraces a pragmatic and modestly perfectionist version of liberalism. It accepts, on the one hand, that in pluralistic democratic societies people have divergent perfectionist visions of the good life but acknowledges, on the other hand, that such societies need to share some minimal basic values. The main pragmatic reason to embrace a modestly perfectionist version of liberalism is that a political philosophy should try to build upon as much of the common morality as possible without becoming controversial. More anti-perfectionist versions of liberalism tend to ignore some shared values, whereas more perfectionist versions of liberalism tend to ignore some divergence. ${ }^{4}$

It should be clear that liberalism has quite different connotations in - analytical political philosophy and in day-to-day European politics. Basically, one could say that new labour, green realos and left-wing Christian-democrats and liberals at least implicitly embrace such a pragmatic and modestly perfectionist liberalism, whereas old labour, green fundis and right-wing Christian-democrats and liberals accept these minimal basic values but strive after divergent varieties of a fuller perfectionism in public morality. Left- and right-wing populists and fundamentalists, finally, do not even subscribe to one or more of the minimal liberal values.

\subsection{Needs and Wants}

This paper uses the noun 'need' to refer to things that are always necessary for survival no matter where or when one lives or what specific values one might adhere to. The noun 'want,' on the other hand, refers to things that are only necessary in specific spatial or temporal contexts or for the pursuit of certain specific values. Some scholars might question the very existence of universal (i.e. non-contingent) needs. However, such a full-blown

\footnotetext{
${ }^{4}$ Prominent proponents of a pragmatic and modestly perfectionist liberalism are United States' former President Clinton's advisor Selznick (1992) and United Kingdom's Prime Minister Blair's advisor Giddens (1998).
} 
scepticism would result in the reductio ad absurdum that denies the harsh reality of some primary goods (to use a Rawlsian term) as being necessary for human survival.

\subsection{Rights and Duties}

This paper uses the noun 'right' to indicate that someone is entitled to do or not do something, or to have or not have something being done to him or her. The noun 'duty,' on the other hand, indicates that someone has an obligation (not) to provide or do something to someone else. If someone has a right, someone else must have a corresponding duty. If this were not the case, rights would be empty and loose their meaning. It is however not true, as some intuitive accounts would argue, that for someone to have rights assumes that he/she also has duties. One should recognise that the rights/duties vocabulary is one of the strongest in ethics and political philosophy. This is both the power and the weakness of this vocabulary. The rights/duties vocabulary requires strict reasoning and only claims applicability in the domain of the mandatory. The absence of certain rights/duties thus does not imply that it could not be a good idea to arrange certain things in the domain of the voluntary.

\subsection{Conditional and Unconditional}

This paper uses the adjective 'unconditional' to indicate that some right or duty holds always and everywhere without further qualification in terms of a provided that or unless clause. The adjective 'conditional,' on the other hand, thus indicates that some right or duty is indeed qualified by such a provided that or unless clause.

\subsection{Positive and Negative}

This paper uses the adjective 'negative' to indicate a duty to refrain from or a right to be restrained from interference with some choice. To have a negative duty thus basically says that you should not do something, whereas a negative right says that something should not be done to you. The adjective 'positive' on the other hand indicates that you are entitled to (do) something (positive right) or that someone else owes (or must do) something to you (positive duty).

\subsection{Reasonable and Non-reasonable}

This paper uses the adjective 'reasonable' first and foremost in the rather modest sense that values and consumptive choices will qualify as reasonable, if people arrived at those values and choices under conditions of adequate information or knowledge and on properly functioning markets. The properly functioning clause is the market equivalent of the Rawlsian well-ordered clause in well-ordered societies. Just as it does not make much sense to talk about justice in a political context that simply does not ensure some basic democratic values, it does not make much sense to talk about reason in a market context that simply does not ensure a level playing field between competitors, i.e. prices need to reflect costs. ${ }^{5}$

Furthermore the adjective 'reasonable' is restricted to the (egalitarian) realm of values and choices that do not harm others (harm principle) (Feinberg 1987) and do not entail

\footnotetext{
${ }^{5}$ This is perfectly in line with the idea of a negative morality as defended by Honneth (1995) and Allen (2001). 
negative repercussions on distributive justice (justice principle) (Rawls 1972). This restriction is indeed only acceptable for people with a willingness to embrace the basic values of liberty and justice for all. The adjective 'non-reasonable,' on the other hand, thus indicates that some value or consumptive choice does not meet even a rather limited interpretation of rationality or is at odds with respect for the harm or justice principles.

\subsection{Superficial and Non-superficial}

This paper uses the adjective 'non-superficial' to indicate that some consumptive value or preference is an expression of some vision of the right or the good, which implies that not being able to act upon that value has negative repercussions for the constitution of some individual or collective identity. The adjective 'superficial,' on the other hand, is reserved for the more shallow preferences without such existential connotations.

\subsection{Overlapping and Non-overlapping}

This paper uses the adjective 'overlapping' to indicate that some value is shared and noncontroversial within some society that is otherwise pluralistic on moral issues. The adjective 'non-overlapping,' on the other hand indicates that some value is controversial and thus not shared by all people in a certain society. ${ }^{6}$

\subsection{Providing and Tracing}

This paper uses the verbs 'providing' and 'tracing' to distinguish between the product and information parts of the product-information combinations that are the subject of divergent traceability schemes. It is, however, important to acknowledge that traceability schemes are always about a 'package deal' of providing products and tracing information.

\subsection{Regulating and Facilitating}

This paper uses the verbs 'regulating' and 'facilitating' to distinguish between directive and non-directive strategies of government intervention in food markets. Whereas the former strategies oblige market actors to behave in certain ways, the latter strategies merely entice these actors into certain practices. Regulating is thus a strategy of public management in the mandatory domain, whereas facilitating is a strategy of public-private governance in the voluntary domain.

\subsection{Consumers, Producers and Regulators}

This paper uses the noun 'consumers' for the people buying, preparing and eating foods that are grown, processed and sold by people referred to as 'producers.' The noun 'regulators' is reserved for people in public, private or public-private bodies that somehow have a responsibility to contribute to a properly functioning market exchange between consumers

\footnotetext{
${ }^{6} \mathrm{~A}$ first indication of what values are overlapping - and the same holds true for what values are reasonable and non-superficial - in a certain liberal-democratic society is to be found in the relative popularity of the different political parties in the elections for its representative institutions (i.e. the parliament). This knowledge may be deepened by engaging citizens/consumers in participatory processes of opinion-formation (see: Beekman et al. 2006) and with qualitative and quantitative social scientific studies using methods like focus groups, in-depth interviews and surveys.
} 
and producers. This paper basically tries to argue which rights to informed choice consumers might have and then formulates the corresponding duties of producers and regulators. It is, however, important to recognise that the development of ethical traceability schemes should be based on a balanced account of rights and duties among all affected parties.

\section{Traceability of Food Safety}

\subsection{Rights of Consumers}

No doubt seems to exist that each and every consumer needs safe food. This need does not vary with the context of consumption and thus does not require any further qualification. This implies that consumers have a positive unconditional right to be provided with safe food products. This would hold true even if historically - and geographically - the right to safe food has not always - and everywhere - been recognised as such.

\subsection{Duties of Producers}

If consumers have a positive unconditional right to be provided with safe food products, producers will have a positive unconditional duty to provide safe food products. This duty is only qualified by a non-moral clause that what counts as safe is always contingent upon available knowledge. This means that a duty to provide safe food products does not call upon producers to strive after a theoretically and practically unfeasible zero-risk. It does call upon producers to minimise food-borne health risks. Furthermore, in a context of food production chains with more than two links the duty to provide safe food products implies a further duty to trace information about the safety of food products.

\subsection{Duties of Regulators}

If needs inform rights and duties of different groups of actors in society, it will be the duty of regulators in a well-ordered liberal-democratic society to ensure that rights are respected by corresponding duties. This implies that with respect to consumers' right to safe food products, in a context of food production chains with more than two links, regulators have positive unconditional duties to secure the safety of food products by developing and enforcing traceability regulations. The whole argument about traceability and food safety is focused on the provision of safe products and the provision of information is only instrumental to that objective.

\section{Non-reasonable and/or Superficial Food Values}

Moving from the domain of needs to the domain of wants, it is not too difficult to see that not all wants or values with respect to food offer sound reasons to argue for rights and duties on the part of different groups of actors. Two borderline cases should suffice to clarify this point. First, nobody will disagree that a cannibal does not have a valid claim to be provided with meat from involuntarily farmed humans. Some food values are simply beyond the realm of permissible values within well-ordered, liberal-democratic societies because they impose infringements on the harm principle or the justice principle. It is of 
course contingent where the exact demarcation between reasonable and non-reasonable food values is to be drawn.

Second, nobody will disagree that someone's preference for blackberries and distaste for blueberries does not provide sufficient reason to claim a right to be provided with blackberry pudding. Talking about rights and duties would lose any meaning if it were not confined to values that transgress some level of superficiality. Again, the exact demarcation between superficial and non-superficial values is of course a matter of contingent discourse.

\section{Reasonable and Non-superficial Food Values}

It seems that in contemporary European societies the whole plethora of consumer concerns that count as expressions of reasonable and non-superficial food values could be summarised into six categories (see, e.g., Beekman et al. 2006):

- Concerns about impacts on public and personal health;

- Concerns about impacts of genetic modification;

- Concerns about impacts on animal welfare;

- Concerns about impacts on the natural environment;

- Concerns about impacts on international justice;

- Concerns about the preservation of regional foods.

It is important to acknowledge a relevant difference between the first two concerns (health and genetic modification) and the last four concerns. Whereas it is perfectly possible to test products to ensure the accuracy of information about food safety or genetically modified ingredients, such a proof of the pudding is not available for the latter concerns. In colloquial terms, animal-friendly and animal-unfriendly, environment-friendly and environment-unfriendly, fairly traded and unfairly traded, and regional and blended food products are substantially equivalent, i.e. such differences in production processes do not impact on the biochemical properties of food products. These qualities can only be verified with the help of recorded identifications of product (hi)stories through the food chain.

All six concerns might be classified as substantive or end concerns to distinguish them from procedural or instrumental concerns about things like transparency, involvement, responsibility, trustworthiness and authenticity. Bluntly speaking, people mostly have procedural concerns because they are substantively concerned about public and personal health, genetic modification, animal welfare, the natural environment, international justice or regional foods. That is why procedural concerns may also be described as instrumental concerns, and that is why it is rather meaningless to discuss these concerns independently of the substantive or end concerns. This would be a confusion of ends and means. Whereas the substantive concerns refer to reasonableness in terms of the harm and justice principles, the procedural concerns refer to reasonableness in terms of adequate information/ knowledge and properly functioning markets.

All six concerns share the characteristic that they go beyond merely personal interests like availability, convenience, price and taste. They are thus properly termed moral concerns.

\subsection{Rights of Consumers}

The fact - or assumption - of value pluralism within contemporary affluent societies implies that more than one set or hierarchy of reasonable and non-superficial food values exists or might 
exist. However, this does not yet seem enough to argue that consumers have a positive conditional right to be provided with food products that meet their values. It does seem reasonable to argue that consumers have a negative conditional right not to be - deliberately misinformed about morally relevant product or process characteristics of foods.

However, one should not ignore the possibility of the existence of some overlapping consensus that holds that, e.g., eggs, meat and milk from livestock production systems should adhere to some minimal standard of animal welfare. ${ }^{7}$ Then, the focus changes from information to products and it does seem reasonable to argue that such cases call for a positive conditional right to be provided with certain foods. The condition is, of course, that - unlike needs such as food safety - these overlapping values are contingent.

\subsection{Duties of Producers}

If consumers have a negative conditional right not to be - deliberately - misinformed about product and process characteristics that are relevant for some reasonable, non-superficial and non-overlapping food value, it will follow that producers have a corresponding negative conditional duty not to misinform consumers about these characteristics of their food products. The impacts of this duty are actually rather strong, since it would imply considerable changes to prevailing marketing practices.

\subsection{Duties of Regulators}

Negative conditional rights and duties, on the one hand, call upon the government to develop regulatory assurances that these rights are respected by corresponding duties. The duty of regulators is, on the other hand, to regulate the development of ethical traceability schemes as means towards the end of establishing market niches or segments for consumers and producers with similar food values.

\section{Concerns About Impacts of Genetic Modification}

It might be wise to provide some further clarification of these points by exploring three possible consumer concerns with respect to the much-debated yet ill-understood case of foods with genetically modified (GM) ingredients. ${ }^{8}$

\subsection{Health}

First, it might be possible to have concerns about negative repercussions of foods with GM ingredients for public or personal health. If these concerns are at least supported by enough

\footnotetext{
${ }^{7}$ The development of an animal welfare monitoring, traceability and labelling scheme is the subject of the European project 'Welfare Quality' (see: http://www.welfarequality.net).

${ }^{8}$ See, e.g., Hansen (2004) for an unconvincing argument that with respect to consumer autonomy no morally relevant difference exists between negative and positive labelling of foods with GM ingredients, and Rubel and Streiffer (2005) for a reply with an equally unconvincing argument that respecting consumer autonomy calls for positive labelling of foods with GM ingredients. Much of the confusion in this debate results from the fact that what counts as a positive or a negative label depends on an account of normalcy. When using GM ingredients is the normal situation, the absence of such ingredients is a positive product attribute for people with particular food values. Hence, in this situation that very much resembles real life, a 'non-GM' label would qualify as a positive and not as a negative label.
} 
scientific uncertainty about such risks to call upon a precautionary approach, the issue will become a case of needs with a negative unconditional right of consumers not to be provided with foods with GM ingredients until their safety has been established beyond reasonable doubt. Producers and regulators will then have the corresponding negative unconditional duties. If these concerns are not supported by some scientific uncertainty, as seems to be the case in real life (see: Kuiper et al. (eds.) 2004), the issue will become a case of nonreasonable concerns with no rights for consumers and no duties for producers and regulators. This first possibility could thus be translated into cases of either needs or nonreasonable wants.

\subsection{Justice}

Second, it might be possible to have concerns about negative repercussions of foods with GM ingredients for either developing countries (an issue of intragenerational justice) or the natural environment (an issue of intergenerational justice). This is where old-school Rawlsians (following 'A theory of justice,' Rawls 1972) and new-school Rawlsians (following 'Political liberalism,' Rawls 1993) will part. The first group of liberals would argue that it is enough to imagine a hypothetical overlapping consensus on the principles of intra- and intergenerational justice that could be reached, if the power of reasonable argument determined the outcome of socio-political discussions. The second group of liberals would argue that one needs an actual overlapping consensus to support positive conditional rights of consumers to be provided with foods without GM ingredients and to support the corresponding positive conditional duties of producers and regulators.

\subsection{Naturalness}

Third, it might be possible to have concerns about foods with GM ingredients because they interfere with either the order of nature or the creation of God. Such concerns are often voiced in public debate but they cannot count on a supportive overlapping consensus. This is where anti-perfectionist Rawlsian liberals, perfectionist liberals (e.g. Raz 1986) and perfectionist communitarians part. The difference between perfectionists and antiperfectionists is that the latter argue that governments should somehow be neutral with respect to different visions of the good life, whereas the former argue that governments should be allowed to promote one or more specific visions of the good life. ${ }^{9}$

Anti-perfectionist liberals cannot see how producers and regulators in liberal-democratic societies could have positive conditional duties to ensure the preservation of the specific visions of the good that inform such concerns. They do, however, acknowledge the existence of negative conditional duties of producers and regulators that should ensure that consumers with these food values are not misinformed on labels that qualify certain foods as non-GM. Perfectionist liberals, on the contrary, do believe that producers and regulators have positive conditional duties to ensure opportunities to choose from a wide range of, e.g., regional foods. Otherwise consumers' freedom of choice would be an empty right. Communitarians even believe that producers and regulators have positive conditional duties to ensure the preservation of specific visions of the good. Hitherto, however, no convincing arguments have been formulated that this latter communitarian position could be in accordance with liberal-democratic governments.

\footnotetext{
${ }^{9}$ Wall and Klosko (2003) edited a collection of essays that offers a good introduction to the perfectionism debate in liberal political philosophy.
} 


\section{Overlapping and Non-overlapping Food Values}

The above explorations might be summarised in more general terms - transgressing the case of foods with GM ingredients - by distinguishing two sub-categories of reasonable and non-superficial food values.

If these values are supported by an overlapping consensus, ethical traceability should be developed as a public management, or business-to-business, tool to achieve the wanted changes in food production processes. It seems that concerns about animal welfare, the natural environment and international justice are based on overlapping, reasonable and nonsuperficial food values in present-day European societies. These concerns thus warrant regulatory enforcement of certain minimum standards of animal welfare, environmentfriendliness and fair trade. Actually, this is not a case of informed choice but of reduced choice; the objective being to remove animal-unfriendly, environment-unfriendly and unfairly traded food products from the shelves of the supermarket. This implies that with respect to overlapping, reasonable and non-superficial food values, liberal-democratic governments are justified to enforce certain moral standards of production with rules and regulations. In a context of food production chains with more than two links this furthermore implies an obligation to record information about these standards of production by means of ethical traceability schemes.

If these values, on the other hand, are not supported by an overlapping consensus, ethical traceability should be developed as a public-private governance, or business-to-consumer, tool to achieve the wanted changes in food information processes. The private side of this governance tool consists of voluntary positive labelling and tracing of food products with specific ethically relevant product and process characteristics (e.g. region of origin or higher than minimum standards of animal welfare, environment-friendliness and fair trade). The public side of this governance tool consists of safeguarding consumers' negative conditional right not be misinformed by corporate marketing. Without this negative right there would be no point in positive labelling, since consumers would then not be able to judge the trustworthiness of the claims on food products. Notice also that a positive conditional information right, which would call for mandatory positive labelling, is almost too absurd to be discussed. Consider, for example, the case of a producer of environmentfriendly candy bars, who is for some reason unwilling to label these candy bars as environment-friendly - this is a real life case! Why on earth, and how in practical terms should and could a government enforce positive labelling upon this producer?

\section{Conclusion}

The whole argument of this paper suggests that two versions of ethical traceability find justification. The first is ethical traceability as a public management tool, used to ensure that consumers are provided with foods that respect some threshold level of animal welfare, sustainability (natural environment) or fair trade (international justice), as supported by a contingent overlapping consensus of food values (several Eurobarometer studies suggest that such an overlapping consensus on these issues indeed exists). Such ethical traceability schemes are intended to ensure that corporate standards and quality assurances are verified by documented product (hi)stories. Concerns about public and personal health are excluded here, since food safety is not a want but a need and thus already covered by traceability schemes without the adjective 'ethical.' Concerns about genetic modification are excluded from this whole market application domain, since these concerns are not supported by an 
overlapping food value consensus. Concerns about regional foods are excluded from the whole market application domain, since it is fundamental to the nature of these concerns that they are only applied to specific food products.

The second version is ethical traceability as a public-private governance tool, used to allow certain consumers to be provided with food products, and sufficient information about these products, that are relevant for reasonable, non-superficial values that are not supported by an overlapping consensus. Governments should then facilitate this in the sense that consumers are not provided with misinformation about product and process characteristics of foods that are relevant for reasonable, non-superficial values that are not supported by an overlapping consensus in contemporary European market democracies.

It is important to notice that these justified versions of ethical traceability should both speak about product-information combinations (and not merely about information), and that in both justified versions of ethical traceability improvements in the tracing of information are instrumental to improvements in the provision of products with some substantive added value. The question then arises of what the two distinguished ethical traceability regimes as management and governance tool respectively - might look like. Table 2 thus spells out the details of the two versions of ethical traceability.

The second version of ethical traceability might be further developed in terms of policy recommendations with respect to the development of ethical traceability schemes for specified niche markets. It is important to rebut the common misunderstanding that niche markets are small. The defining characteristic of a niche market is that it is a meeting place for just one segment of producers and consumers. This segment might be or become a quite large portion of the whole market. Criteria and indicators need to be developed for a (higher than minimum) standard of labelled food products for specified niche markets. Furthermore, the nature of the demand for and provision of information by consumers,

Table 2 Two versions of ethical traceability

\begin{tabular}{|c|c|c|}
\hline & Ethical traceability as a management tool & Ethical traceability as communication tool \\
\hline Values & $\begin{array}{l}\text { Reasonable, non-superficial and overlapping } \\
\text { food values }\end{array}$ & $\begin{array}{l}\text { Reasonable, non-superficial and non- } \\
\text { overlapping food values }\end{array}$ \\
\hline $\begin{array}{l}\text { Application } \\
\text { domain }\end{array}$ & Whole market & Niche markets \\
\hline Who & All producers & Some consumers and producers \\
\hline \multirow[t]{5}{*}{ Concerns } & Animal welfare & Genetic modification \\
\hline & Natural environment & Animal welfare \\
\hline & International justice & Natural environment \\
\hline & & International justice \\
\hline & & Regional foods \\
\hline Standard & Minimum & Higher \\
\hline Emphasis & Products & Information \\
\hline Labelling & No & Yes \\
\hline $\begin{array}{l}\text { Responsibilities } \\
\text { consumers }\end{array}$ & None & $\begin{array}{l}\text { Willingness to pay higher prices for } \\
\text { labelled foods with specific product or } \\
\text { process characteristics }\end{array}$ \\
\hline $\begin{array}{l}\text { Responsibilities } \\
\text { regulators }\end{array}$ & $\begin{array}{l}\text { Develop, apply and enforce regulations to } \\
\text { guarantee specific product and process } \\
\text { characteristics of foods }\end{array}$ & $\begin{array}{l}\text { Develop, apply and enforce regulations } \\
\text { about labelling of foods with specific } \\
\text { product and process characteristics }\end{array}$ \\
\hline $\begin{array}{l}\text { Responsibilities } \\
\text { producers }\end{array}$ & Obey regulations & Truthful labelling \\
\hline
\end{tabular}


retailers, food processing companies, farmers and input companies (e.g. feed and seed) need to be spelled out. Together these criteria, indicators, information flows specify ethical traceability schemes.

Acknowledgements This paper presented results of the project 'Ethical traceability and informed choice in food ethical issues' as funded by the European Commission, DG Research, under FP6, Science and Society Programme. I would like to thank Tassos Michalopoulos for our lively discussions about the morality of the market. His modestly different conclusions from these discussions are voiced in his paper 'The citizen goes shopping' (Michalopoulos 2006). I would also like to thank Lindy Sharpe for her corrections of my nonnative English.

\section{References}

Allen J (2001) The place of negative morality in political theory. Polit Theory 29(3):337-363

Beekman V (2000) You are what you eat: meat, novel protein foods, and consumptive freedom. J Agric Environ Ethics 12(2):185-196

Beekman V, de Bakker E, Baranzke H, Baune O, Deblonde M, Forsberg EM, de Graaff R, Ingensiep HW, Lassen J, Mepham B, Porsborg Nielsen A, Tomkins S, Thorstensen E, Millar K, Skorupinski B, Brom F, Kaiser M, Sandoe P (2006) Ethical bio-technology assessment tools for agriculture and food production. Final Report Ethical Bio-TA Tools (QLG6-CT-2002-02594). LEI, The Hague

Brom FWA (2000) Food, consumer concerns, and trust: food ethics for a globalizing market. J Agric Environ Ethics 12(2):127-139

Coff C (2004) Fair trade and ethical traceability. Paper presented at the European Parliament, Brussels, March

Coff C, Korthals M, Barling D (2007) Ethical traceability and informed food choice. In: Coff C, Barling D, Korthals M, Nielsen T (eds) Ethical traceability and communicating food. Springer, Dordrecht (Autumn 2007)

Feinberg J (1987) Harm to others. Oxford University Press, Oxford

Giddens A (1998) The third way. The renewal of social democracy. Polity Press, Cambridge

Hansen K (2004) Does autonomy count in favour of labelling genetically modified food? J Agric Environ Ethics 17(1):67-76

Hirschauer N (2004) A model-based approach to moral hazard in food chains. What contribution do principal-agent-models make to the understanding of food risks induced by opportunistic behaviour? Agrarwirtschaft - German J Agric Econ 53:192-205

Honneth A (1995) Moral consciousness and class domination: some problems in the analysis of hidden morality. In: Wright CW (ed) The fragmented world of the social: essays in social and political philosophy by Axel Honneth. State University of New York Press, New York

Korthals M (2001) Taking consumers seriously: two concepts of consumer sovereignty. J Agric Environ Ethics 14(2):201-215

Kuiper HA, Kleter GA, Konig A, Hammes WP, Knudsen I (eds) (2004) Safety assessment, detection and traceability, and societal aspects of genetically modified foods. Food Chem Toxicol 42(7):1043-1202

Kymlicka W (1990) Contemporary political philosophy: an introduction. Oxford University Press, Oxford

Michalopoulos T (2006) The citizen goes shopping: what do the peers have to say about it? In: Kaiser M, Lien ME (eds) Ethics and the politics of food. Wageningen Academic Publishers, Wageningen, pp 483-487

Rawls J (1972) A theory of justice. Oxford University Press, Oxford

Rawls J (1993) Political liberalism. Columbia University Press, New York

Raz J (1986) The morality of freedom. Clarendon, Oxford

Rippe KP (2000) Novel foods and consumer rights. Concerning food policy in a liberal state. J Agric Environ Ethics 12(2):71-80

Rubel A, Streiffer R (2005) Respecting the autonomy of European and American consumers: defending positive labels on GM foods. J Agric Environ Ethics 18(1):75-84

Selznick P (1992) The moral commonwealth. Social theory and the promise of community. University of California Press, Berkeley/Los Angeles

Wall S, Klosko G (eds) (2003) Perfectionism and neutrality. Essays in liberal theory. Rowman \& Littlefield, Boston 